\title{
Fixed Point Theorems for Geraghty Type Contractive Mappings and Coupled Fixed Point Results in 0-Complete Ordered Partial Metric Spaces
}

\author{
Esra Yolacan \\ Republic of Turkey Ministry of National Education, 60000 Tokat, Turkey \\ Correspondence should be addressed to Esra Yolacan; yolacanesra@gmail.com
}

Received 26 April 2016; Accepted 3 July 2016

Academic Editor: Shusen Ding

Copyright (C) 2016 Esra Yolacan. This is an open access article distributed under the Creative Commons Attribution License, which permits unrestricted use, distribution, and reproduction in any medium, provided the original work is properly cited.

We establish new fixed point theorems in 0-complete ordered partial metric spaces. Also, we give remark on coupled generalized Banach contraction. Some examples illustrate the usability of our results. The theorems presented in this paper are generalizations and improvements of the several well known results in the literature.

\section{Introduction and Preliminaries}

Henceforward, the letters $\mathbb{R}, \mathbb{R}^{+}$, and $\mathbb{N}$ will indicate the set of real numbers, the set of nonnegative real numbers, and the set of positive integer numbers, respectively.

Definition 1 (see [1]). A partial metric on a nonempty set $X$ is a function $P: X^{2} \rightarrow \mathbb{R}^{+}$such that, for all $x, y, z \in X,(P 1)$ $x=y \Leftrightarrow P(x, x)=P(x, y)=P(y, y),(P 2) P(x, x) \leq P(x, y)$, (P3) $P(x, y)=P(y, x)$, and $(P 4) P(x, y) \leq P(x, z)+P(z, y)-$ $P(z, z)$. The pair $(X, P)$ is called a partial metric space.

If $P$ is a partial metric on $X$, then the function $P^{s}: X^{2} \rightarrow$ $\mathbb{R}^{+}$given by $P^{s}(x, y)=-P(y, y)-P(x, x)+2 P(x, y)$ is a metric on $X$. Each partial metric $P$ on $X$ introduces a $T_{0}$ topology $\tau_{P}$ on $X$ which has as a base the family of open balls $B_{P}(x, \varepsilon)=$ $\{p \in X: P(x, p)<P(x, x)+\varepsilon\}$ for all $x \in X$ and $\varepsilon>0$.

Let $(X, P)$ be a partial metric space, and let $\left\{x_{n}\right\}$ be any sequence in $X$ and $x \in X$. Then (i) a sequence $\left\{x_{n}\right\}$ is convergent to $x$ with respect to $\tau_{P}$, if $P\left(x_{n}, x\right) \rightarrow P(x, x)$ as $n \rightarrow \infty$, (ii) a sequence $\left\{x_{n}\right\}$ is a Cauchy sequence in $(X, P)$ if $\lim _{n, m \rightarrow \infty} P\left(x_{n}, x_{m}\right)$ exists and is finite; (iii) $(X, P)$ is called complete if for every Cauchy sequence $\left\{x_{n}\right\}$ in $X$ there exists $x \in X$ such that $P\left(x_{n}, x_{m}\right) \rightarrow P(x, x)$ as $n, m \rightarrow \infty$.

Romaguera [2] introduced the notion of 0-Cauchy sequence, 0 -complete partial metric spaces and proved some characterizations of partial metric spaces in terms of completeness and 0 -completeness. After that many authors extended the results of [2] and studied fixed point theorems in 0 -complete partial metric space (see [2-10]).

Definition 2 (see [2]). Let $(X, P)$ be a partial metric space. A sequence $\left\{x_{n}\right\}$ in $X$ is called a 0 -Cauchy sequence if $P\left(x_{n}, x_{m}\right) \rightarrow 0$ as $n, m \rightarrow \infty$. The space $(X, P)$ is said to be 0 -complete if every 0 -Cauchy sequence in $X$ converges with respect to $\tau_{P}$ to a point $x \in X$ such that $P(x, x)=0$.

Remark 3 (see $[11,12])$. (1) Let $(X, P)$ be a partial metric space. If $P\left(x_{n}, \rho\right) \rightarrow P(\rho, \rho)=0$ as $n \rightarrow \infty$, then $P\left(x_{n}, y\right) \rightarrow P(\rho, y)$ as $n \rightarrow \infty$ for all $y \in X$.

(2) If $f: X \rightarrow X$ is a continuous at $\rho$, then for each sequence $\left\{x_{n}\right\}$ in $X$, we have $P\left(x_{n}, \rho\right) \rightarrow P(\rho, \rho)=0$ as $n \rightarrow \infty \Rightarrow P\left(f x_{n}, f \rho\right) \rightarrow P(f \rho, f \rho)=0$ as $n \rightarrow \infty$ (see [5]).

Let $\mathrm{F}$ be the class of functions $\theta:[0, \infty) \rightarrow[0,1)$ with $\theta\left(t_{n}\right) \rightarrow 1$ implying $t_{n} \rightarrow 0$. Amini-Harandi and Emami [13] presented the following results.

Theorem 4 (see [13]). Let $(X, \preccurlyeq)$ be an ordered set endowed with a metric $d$ and let $f: X \rightarrow X$ be agiven mapping. Suppose that the following conditions hold:

(i) $(X, d)$ is complete. 
(ii)

(1) $f$ is continuous or

(2) if a nondecreasing sequence $\left\{x_{n}\right\}$ in $X$ converges to some point $x \in X$, then $x_{n} \leqslant x$ for all $n \in \mathbb{N}$.

(iii) $f$ is nondecreasing.

(iv) There exists $x_{0} \in X$ such that $x_{0} \leqslant f x_{0}$.

(v) There exists $\theta \in \mathrm{F}$ such that for all $x, y \in X$ with $x \geqslant y$,

$$
d(f x, f y) \leq \theta(d(x, y)) d(x, y) .
$$

Then $f$ has a fixed point. Moreover, if for all $(x, y) \in X^{2}$ there exists a $z \in X$ such that $x \leqslant z$ and $y \leqslant z$, we obtain uniqueness of the fixed point.

In this paper, we establish new fixed point theorems in 0complete ordered partial metric spaces (briefly 0-COPMS). Also, we give remark on coupled generalized Banach contraction. Some examples illustrate the usability of our results. The theorems presented in this paper are generalizations and improvements of the several well known results in the literature.

\section{Main Results}

Theorem 5. Let $(X, P)$ be a 0 -COPMS. Let $f: X \rightarrow X$ be a nondecreasing mapping such that

$$
P(f x, f y) \leq \theta(P(x, y)) P(x, y)
$$

for all $x, y \in X$ with $x \geqslant y($ or $y \geqslant x)$ and $\theta \in \mathrm{F}$. Also suppose that there exists $x_{0} \in X$ such that $x_{0} \leqslant f x_{0}\left(\right.$ or $\left.x_{0} \geqslant f x_{0}\right)$. One assumes

(1) $f$ is continuous or

(2) if a nondecreasing sequence $\left\{x_{n}\right\}$ in $X$ converges to some point $x \in X$, then $x_{n} \leqslant x\left(\right.$ or $\left.x_{n} \geqslant x\right)$ for all $n \in \mathbb{N}$.

Then $f$ has a fixed point $\rho$.

Proof. By assumption there exists $x_{0} \in X$ such that $x_{0} \leqslant f x_{0}$. Define $x_{1} \in X$ as $x_{1}=f x_{0}$. Then we have $x_{1} \geqslant x_{0}$. In a similar manner, we get $x_{2} \in X$ as $x_{2}=f x_{1}$. In that case, $x_{2}=f x_{1} \geqslant f x_{0}=x_{1}$. Continuing this procedure we have $\left\{x_{n}\right\}$ in $X$ such that

$$
f x_{n}=x_{n+1}, \quad n \in \mathbb{N} .
$$

If $x_{n+1}=x_{n}$ for some $n \in \mathbb{N}$, then the proof is completed. Suppose farther that $x_{n+1} \neq x_{n}$ for each $n \in \mathbb{N}$. Consider, as $f$ is nondecreasing, we obtain that

$$
\begin{aligned}
x_{0} & \leqslant f x_{0}=x_{1} \preccurlyeq f x_{1}=x_{2} \preccurlyeq \cdots \preccurlyeq x_{n}=f x_{n-1} \preccurlyeq x_{n+1} \\
& =f x_{n} \leqslant \cdots .
\end{aligned}
$$

From (2), (3), and (4), for all $n \geq 1$, we get that

$$
\begin{aligned}
P\left(x_{n+1}, x_{n+2}\right) & =P\left(f x_{n}, f x_{n+1}\right) \\
& \leq \theta\left(P\left(x_{n}, x_{n+1}\right)\right) P\left(x_{n}, x_{n+1}\right) \\
& \leq P\left(x_{n}, x_{n+1}\right) .
\end{aligned}
$$

Then $\left\{P\left(x_{n}, x_{n+1}\right)\right\}$ is a monotone decreasing. Hence $P\left(x_{n}\right.$, $\left.x_{n+1}\right) \rightarrow c \geq 0$ as $n \rightarrow \infty$. Assume $c>0$. Then by (2) we have

$$
\frac{P\left(x_{n+1}, x_{n+2}\right)}{P\left(x_{n}, x_{n+1}\right)} \leq \theta\left(P\left(x_{n}, x_{n+1}\right)\right) .
$$

Equation (6) yields $\theta\left(P\left(x_{n}, x_{n+1}\right)\right) \rightarrow 1$ as $n \rightarrow \infty$. By virtue of $\theta \in \mathrm{F}$, this implies that

$$
P\left(x_{n}, x_{n+1}\right) \longrightarrow 0 \quad \text { as } n \longrightarrow \infty .
$$

Now we claim that $\left\{x_{n}\right\}$ is a 0 -Cauchy sequence. Conversely, suppose that

$$
\lim \sup _{n, m \rightarrow \infty} P\left(x_{n}, x_{m}\right)>0 .
$$

By (P4) and (2), we have, for $n>m$,

$$
\begin{aligned}
P\left(x_{n}, x_{m}\right) \leq & P\left(x_{n}, x_{n+1}\right)+P\left(x_{n+1}, x_{m+1}\right) \\
& +P\left(x_{m+1}, x_{m}\right)-P\left(x_{m+1}, x_{m+1}\right) \\
& -P\left(x_{n+1}, x_{n+1}\right) \\
\leq & P\left(x_{n}, x_{n+1}\right)+P\left(x_{m+1}, x_{m}\right) \\
& +\theta\left(P\left(x_{n}, x_{m}\right)\right) P\left(x_{n}, x_{m}\right) \\
\leq & \frac{P\left(x_{n}, x_{n+1}\right)+P\left(x_{m+1}, x_{m}\right)}{1-\theta\left(P\left(x_{n}, x_{m}\right)\right)} .
\end{aligned}
$$

Owing to (7) and (8), we get that

$$
\lim _{n, m \rightarrow \infty} \frac{1}{1-\theta\left(P\left(x_{n}, x_{m}\right)\right)}=\infty
$$

from which we have $\lim _{n, m \rightarrow \infty} \theta\left(P\left(x_{n}, x_{m}\right)\right) \geq 1$ which implies $\lim _{n, m \rightarrow \infty} \theta\left(P\left(x_{n}, x_{m}\right)\right)=1$. Since $\theta \in \mathrm{F}$, we obtain $\lim _{n, m \rightarrow \infty} P\left(x_{n}, x_{m}\right)=0$. It is a contradiction. Thus $\left\{x_{n}\right\}$ is a 0 -Cauchy sequence. As $(X, P)$ is 0 -complete, it follows that there exists $\rho \in X$ such that $x_{n} \rightarrow \rho$ in $(X, P)$ and $P(\rho, \rho)=0$. Furthermore,

$$
\lim _{n \rightarrow \infty} P\left(x_{n}, \rho\right)=P(\rho, \rho)=0 .
$$

We will show that $f \rho=\rho$. Consider two cases.

Case 1. If $f$ is continuous, then

$$
f \rho=\lim _{n \rightarrow \infty} f x_{n}=\lim _{n \rightarrow \infty} x_{n+1}=\rho ;
$$

hence $f \rho=\rho$.

Case 2. If (2) holds, then,

$$
\begin{aligned}
P(\rho, f \rho) & \leq P\left(\rho, x_{n+1}\right)+P\left(x_{n+1}, f \rho\right)-P\left(x_{n+1}, x_{n+1}\right) \\
& \leq P\left(\rho, x_{n+1}\right)+P\left(x_{n+1}, f \rho\right) \\
& \leq P\left(\rho, x_{n+1}\right)+\theta\left(P\left(x_{n}, \rho\right)\right) P\left(x_{n}, \rho\right) \\
& \leq P\left(\rho, x_{n+1}\right)+P\left(x_{n}, \rho\right) .
\end{aligned}
$$

In view of $P\left(x_{n}, \rho\right) \rightarrow 0$ as $n \rightarrow \infty$, then we have $f \rho=\rho$. 
The following is example which illustrate Theorem 5 and that the generalizations are proper.

Example 6. Let $X=[0,+\infty) \cap \mathbb{Q}$, and let $P: X \times X \rightarrow \mathbb{R}^{+}$be defined by $P(x, y)=\max \{x, y\}$ for all $x, y \in X$. Then $(X, P)$ is a $0-C O P M S$. Yet it is not complete partial metric space. We endow $X$ with the partial order

$$
\begin{aligned}
& x \preccurlyeq y \Longleftrightarrow \\
& x=y
\end{aligned}
$$

or $x, y \in[0,1] \quad$ with $x \leq y$.

Let $\theta(t)=(t+1)^{-1}$ for all $t \geq 0$. Then it is clear that $\theta \in \mathrm{F}$. Define $f: X \rightarrow X$ as

$$
f x= \begin{cases}\frac{x^{3}}{1+x^{3}} & x \in[0,1], \\ \frac{1}{x^{2}} & x>1 .\end{cases}
$$

Assume that $y \preccurlyeq x$. Then we have two cases.

Case 1. If $x \in[0,1](y \in[0,1])$, then

$$
\begin{gathered}
P(f x, f y)=\max \left\{\frac{x^{3}}{1+x^{3}}, \frac{y^{3}}{1+y^{3}}\right\}=\frac{x^{3}}{1+x^{3}}, \\
P(x, y)=\max \{x, y\}=x .
\end{gathered}
$$

Therefore, we have

$$
\begin{aligned}
\theta & (P(x, y)) P(x, y)-P(f x, f y)=\frac{x}{1+x}-\frac{x^{3}}{1+x^{3}} \\
\quad= & \frac{x-x^{2}}{1+x^{3}} \geq 0 .
\end{aligned}
$$

Hence, for $x \in[0,1], P(f x, f y) \leq \theta(P(x, y)) P(x, y)$.

Case 2. If $x>1(y=x)$, then

$$
\begin{gathered}
P(f x, f y)=\max \left\{\frac{1}{x^{2}}, \frac{1}{y^{2}}\right\}=\frac{1}{x^{2}}, \\
P(x, y)=\max \{x, y\}=x .
\end{gathered}
$$

Hence, we get

$$
\begin{aligned}
\theta & (P(x, y)) P(x, y)-P(f x, f y)=\frac{x}{1+x}-\frac{1}{x^{2}} \\
& =\frac{x^{3}-x-1}{x^{3}+x^{2}}=1-k \geq 0,
\end{aligned}
$$

where

$$
0<k=\frac{x^{2}+x+1}{x^{3}+x^{2}}<1 .
$$

Thus, for $x>1, P(f x, f y) \leq \theta(P(x, y)) P(x, y)$.
Moreover, by Cases 1 and 2, it is clear that both assumptions (1) and (2) of Theorem 5 are satisfied, and for $x_{0}=0$, we have $x_{0} \leqslant f x_{0}$. Hence, all assumptions of Theorem 5 are satisfied, and $f$ has a fixed point $\rho=0$.

On the contrary, consider Example 6 in the standard metric $d(x, y)$. If $x=1 / 3$ and $y=1$, then

$$
\begin{aligned}
d\left(f \frac{1}{3}, f 1\right) & =\left|\frac{(1 / 3)^{3}}{1+(1 / 3)^{3}}-\frac{1}{2}\right|=0.46 \\
d\left(\frac{1}{3}, 1\right) & =\left|\frac{1}{3}-1\right|=0.66
\end{aligned}
$$

and so

$$
d\left(f \frac{1}{3}, f 1\right)=0.46>0,4=\theta\left(d\left(\frac{1}{3}, 1\right)\right) d\left(\frac{1}{3}, 1\right) .
$$

Thus, $d(f x, f y) \leq \theta(d(x, y)) d(x, y)$ is not satisfied.

\section{Remark on Coupled Generalized Banach Contraction}

The following result generalizes and extends Theorem 2.1. in [14]. When making the proof of the theorem, Radenović's technique [15] is used.

Theorem 7. Let $(X, p)$ be a 0-COPMS and let $f: X^{2} \rightarrow X$ be a mapping. Suppose that, for all $x, y, a, b \in X$ and $\theta \in \mathrm{F}$, the following condition

$$
\begin{aligned}
& p(F(x, y), F(a, b)) \leq \theta\left((p(x, a)+p(y, b)) \times 2^{-1}\right) \\
& \cdot\left((p(x, a)+p(y, b)) \times 2^{-1}\right)
\end{aligned}
$$

holds. Then F has a fixed point.

Proof. Consider the metrics $P: X^{2} \times X^{2} \rightarrow[0, \infty)$ defined by

$$
\begin{aligned}
P(A, B)=p(x, a)+p( & (y, b) \\
& \forall A=(x, y), B=(a, b) \in X^{2} .
\end{aligned}
$$

If $\left(X^{2}, p\right)$ is complete, then $\left(X^{2}, P\right)$ is complete (resp. 0complete), too. Now, define the operator $T: X^{2} \rightarrow X^{2}$ by

$$
T(A)=(F(x, y), F(y, x)), \quad \forall A=(x, y) \in X^{2} .
$$

Let $P^{\prime}: X^{2} \times X^{2} \rightarrow[0, \infty)$ be a metric on $X^{2}$ defined by $P^{\prime}(A, B)=P(A, B) / 2$ for all $A=(x, y), B=(a, b) \in X^{2}$.

From (23), for all $(x, y),(a, b) \in X^{2}$ with $x \leqslant a$ and $y \geqslant b$, we get

$$
\begin{aligned}
& p(F(x, y), F(a, b)) \leq \theta\left((p(x, a)+p(y, b)) \times 2^{-1}\right) \\
& \cdot\left((p(x, a)+p(y, b)) \times 2^{-1}\right), \\
& p(F(b, a), F(y, x)) \leq \theta\left((p(x, a)+p(y, b)) \times 2^{-1}\right) \\
& \quad \cdot\left((p(x, a)+p(y, b)) \times 2^{-1}\right) .
\end{aligned}
$$


This implies that for all $(x, y),(a, b) \in X^{2}$ with $x \leqslant a$ and $y \geqslant b$,

$$
\begin{aligned}
& \{p(F(x, y), F(a, b))+p(F(b, a), F(y, x))\} \times 2^{-1} \\
& \quad \leq \theta\left((p(x, a)+p(y, b)) \times 2^{-1}\right) \\
& \cdot\left((p(x, a)+p(y, b)) \times 2^{-1}\right) ;
\end{aligned}
$$

that is,

$$
P^{\prime}(T(A), T(B)) \leq \theta\left(P^{\prime}(A, B)\right) P^{\prime}(A, B)
$$

which is in fact condition (2), for all $A=(x, y), B=(a, b) \epsilon$ $X^{2}$ with $A=(x, y) \geqslant(a, b)=B$. Hence, all conditions of Theorem 5 are satisfied. In this case, applying Theorem 5 , we have that $T$ has a fixed point. From the definition of $T$, we have $x=F(x, y)$ and $y=F(y, x)$; that is to say, $(x, y)$ is a coupled fixed point of $F$.

Remark 8. If $\theta(t)=k, 0 \leq k<1$ in the inequality (23), then we obtain results of Bhaskar and Lakshmikantham [16] in 0COPMS.

The following example illustrates the case when Theorem 7 is applicable, while Theorem 2.1. in [14] is not.

Example 9. Let $X=[0,1]$, and let $p: X^{2} \rightarrow \mathbb{R}^{+}$be defined by $p(x, y)=\max \{x, y\}+|x-y|$ for all $x, y \in X$. Then $(X, P)$ is a $0-C O P M S$. Yet it is not complete partial metric space. We consider the following order relation on $X$ :

$$
\begin{aligned}
x, y & \in X, \quad x \leqslant y \Longleftrightarrow \\
x & =y \\
\text { or }(x, y) & \in\{(0,0),(0,1),(1,1)\} .
\end{aligned}
$$

Let $\theta(t)=(t+1)^{-1}$ for all $t \geq 0$. Then it is clear that $\theta \in \mathrm{F}$. Define $F: X^{2} \rightarrow X$ as $F(x, y)=(y-x) / 5$ for all $x, y \in X$.

We have the following cases.

Case 1. For $(x, y)=(a, b)=(0,0)$ or $(x, y)=(a, b)=(1$, 1) or $(x, y)=(0,0)$ and $(a, b)=(1,1)$, we have $p(F(x$, $y), F(a, b))=0$. Thus, (23) holds.

Case 2. For $(x, y)=(0,0)$ and $(a, b)=(0,1)$, we have

$$
\begin{gathered}
p(F(0,0), F(0,1))=\frac{2}{5}<\frac{1}{2} \\
=\theta\left((p(0,0)+p(0,1)) \times 2^{-1}\right) \\
\cdot\left((p(0,0)+p(0,1)) \times 2^{-1}\right) .
\end{gathered}
$$

Thus, (23) holds.

Case 3. For $(x, y)=(0,1)$ and $(a, b)=(1,1)$, we have

$$
\begin{gathered}
p(F(0,1), F(1,1))=\frac{2}{5}<\frac{3}{5} \\
=\theta\left((p(0,1)+p(1,1)) \times 2^{-1}\right) \\
\cdot\left((p(0,1)+p(1,1)) \times 2^{-1}\right) .
\end{gathered}
$$

Thus, (23) holds.
Therefore, all the conditions of Theorem 7 are satisfied and $(0,0)$ is a coupled fixed point of $F$.

\section{Competing Interests}

The author declares that she has no competing interests.

\section{References}

[1] S. G. Matthews, "Partial metric topology," Annals of the New York Academy of Sciences, vol. 728, pp. 183-197, 1994.

[2] S. Romaguera, "A Kirk type characterization of completeness for partial metric spaces," Fixed Point Theory and Applications, vol. 2010, Article ID 493298, 6 pages, 2010.

[3] N. Hussain, S. Al-Mezel, and P. Salimi, "Fixed points for $\psi$ graphic contractions with application to integral equations," Abstract and Applied Analysis, vol. 2013, Article ID 575869, 11 pages, 2013.

[4] A. G. B. Ahmad, Z. M. Fadail, V. Ć. Rajić, and S. Radenović, "Nonlinear Contractions in 0-complete partial metric spaces," Abstract and Applied Analysis, vol. 2012, Article ID 451239, 12 pages, 2012.

[5] H. K. Nashine, Z. Kadelburg, S. Radenović, and J. K. Kim, "Fixed point theorems under Hardy-Rogers contractive conditions on 0 -complete ordered partial metric spaces," Fixed Point Theory and Applications, vol. 2012, article 180, 2012.

[6] S. Shukla and S. Radenović, "Some common fixed point theorems for F-contraction type mappings in 0-complete partial metric spaces," Journal of Mathematics, vol. 2013, Article ID 878730, 7 pages, 2013.

[7] S. Shukla, S. Radenović, and C. Vetro, "Set-valued HardyRogers type contraction in 0-complete partial metric spaces," International Journal of Mathematics and Mathematical Sciences, vol. 2014, Article ID 652925, 9 pages, 2014.

[8] S. Shukla, "Set-valued Prešić-Ćirić type contraction in 0complete partial metric spaces," Matematicki Vesnik, vol. 66, no. 2, pp. 178-189, 2014.

[9] D. Paesano and C. Vetro, "Multi-valued F-contractions in 0complete partial metric spaces with application to Volterra type integral equation," Revista de la Real Academia de Ciencias Exactas, Fisicas y Naturales, Serie A: Matematicas, vol. 108, no. 2, pp. 1005-1020, 2014.

[10] M. A. Akturk and E. Yolacan, "Generalized $(\psi, \varphi)$-weak contractions in 0-complete partial metric spaces," Journal of Mathematical Sciences and Applications, vol. 4, no. 1, pp. 14-19, 2016.

[11] T. Abdeljawad, E. Karapınar, and K. Taş, "Existence and uniqueness of a common fixed point on partial metric spaces," Applied Mathematics Letters, vol. 24, no. 11, pp. 1900-1904, 2011.

[12] E. Karapınar and I. M. Erhan, "Fixed point theorems for operators on partial metric spaces," Applied Mathematics Letters, vol. 24, no. 11, pp. 1894-1899, 2011.

[13] A. Amini-Harandi and H. Emami, "A fixed point theorem for contraction type maps in partially ordered metric spaces and application to ordinary differential equations," Nonlinear Analysis: Theory, Methods \& Applications, vol. 72, no. 5, pp. 2238-2242, 2010.

[14] B. S. Choudhury and A. Kundu, "On coupled generalised Banach and Kannan type contractions," Journal of Nonlinear Science and its Applications, vol. 5, no. 4, pp. 259-270, 2012. 
[15] S. Radenović, "Remarks on some coupled. Fixed point results in Partial metric spaces," Nonlinear Functional Analysis and Applications, vol. 18, no. 1, pp. 39-50, 2013.

[16] T. G. Bhaskar and V. Lakshmikantham, "Fixed point theorems in partially ordered metric spaces and applications," Nonlinear Analysis, vol. 65, no. 7, pp. 1379-1393, 2006. 


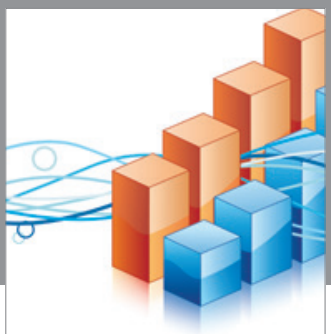

Advances in

Operations Research

vatem alat4

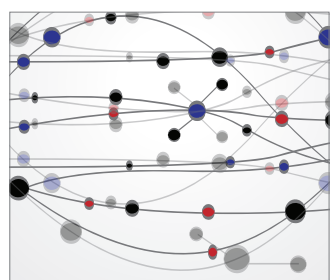

\section{The Scientific} World Journal
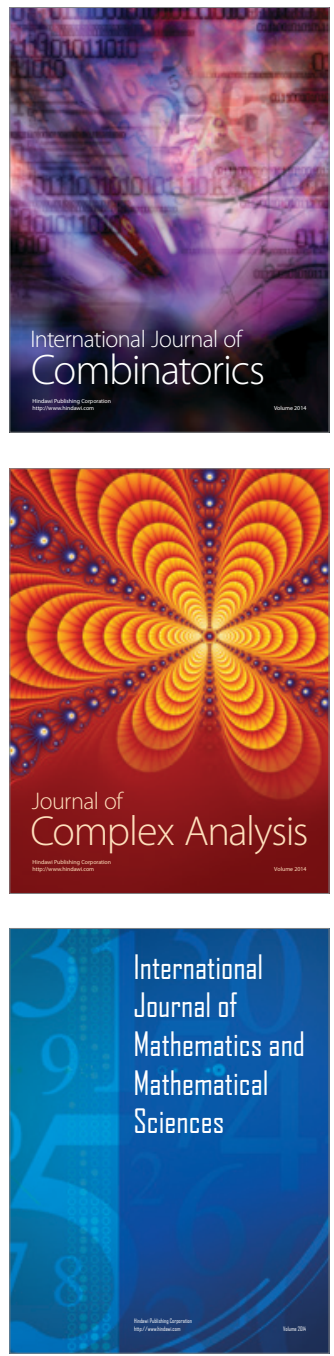
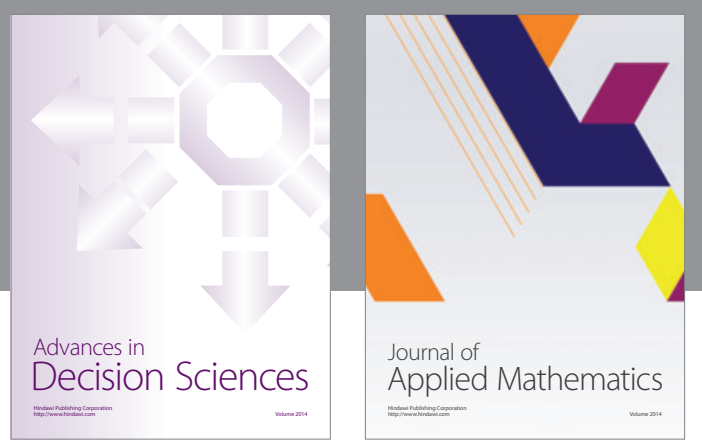

Algebra

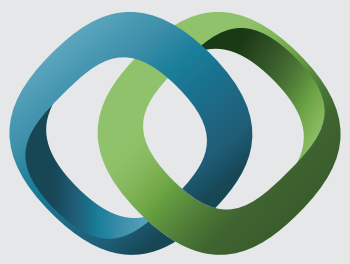

\section{Hindawi}

Submit your manuscripts at

http://www.hindawi.com
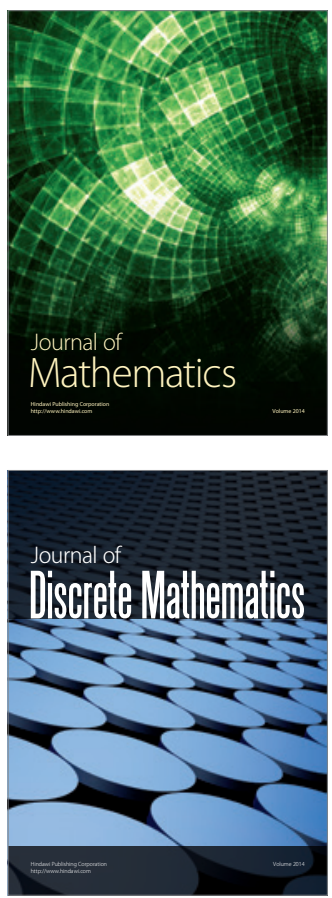

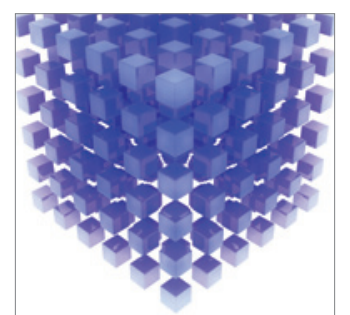

Mathematical Problems in Engineering
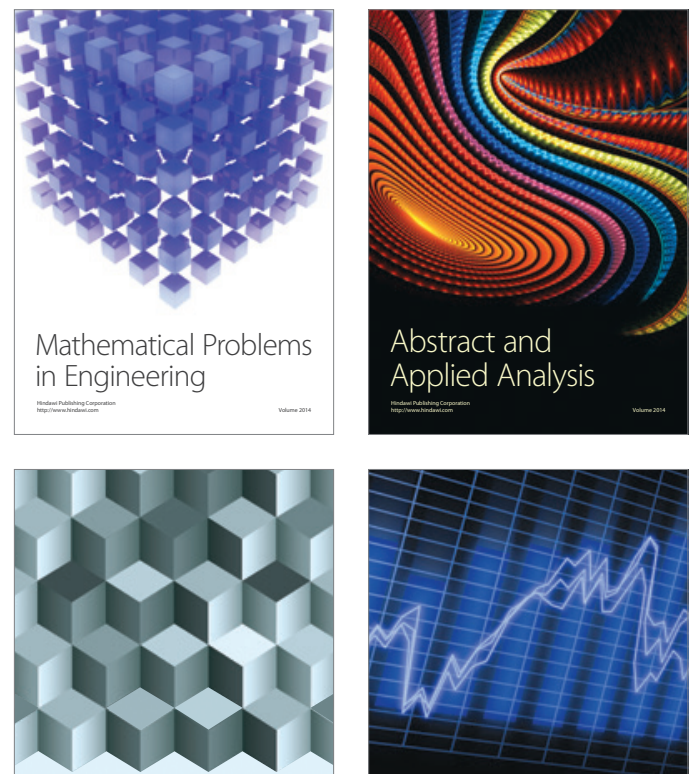

Journal of

Function Spaces

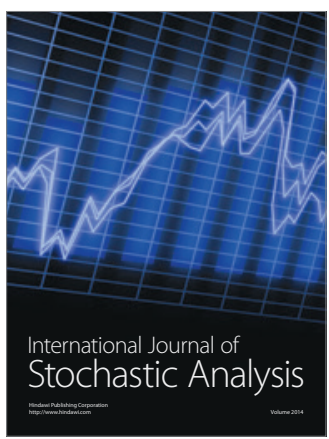

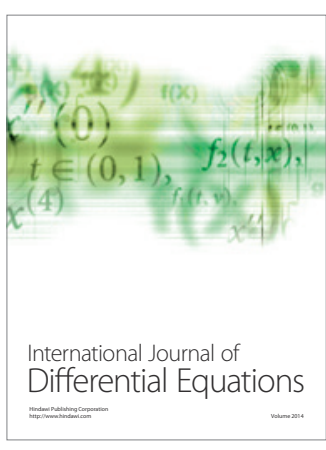
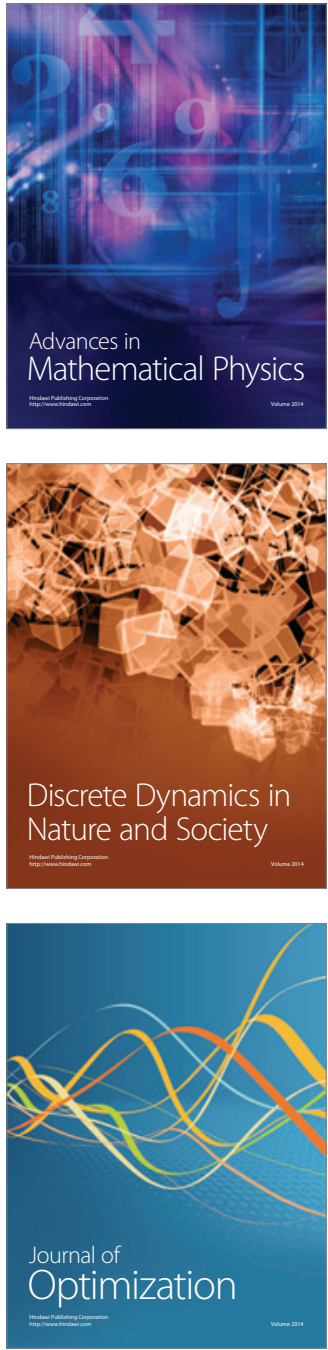